Gut, 1977, 18, 236-239

\title{
Ileorectal anastomosis in patients with Crohn's disease of the colon
}

\author{
G. FLINT, R. STRAUSS, N. PLATT, AND L. WISE
}

From the Departments of Surgery and Pathology, Long Island Jewish-Hillside Medical Center, New Hyde Park, New York, and The Health Sciences Center, State University of New York at Stony Brook, New York, USA

SUMMARY Thirty-seven patients were studied who had an ileorectal anastomosis performed for Crohn's disease of the colon. Twenty-nine were done as a primary procedure and in eight the anastomosis was made after previous total or segmental colectomy. Three patients developed anastomotic leaks and all three patients died. No patient who had a diverting loop ileostomy performed at the time of ileorectal anastomosis developed anastomotic leaks before or after the ileostomy was closed. Of the 37 patients, three died postoperatively and another five have had less than a one year follow-up. Of the remaining 29 patients, $12(41 \%)$ had recurrences in either the rectum or ileum. Half of the recurrences took place five or more years after surgery. Seven of the 12 patients with recurrences have had their anastomoses taken down. When this recurrence rate of $41 \%$ is compared with the recurrence of ileitis in patients after total colectomy and ileostomy for Crohn's disease of the colon, the incidence of recurrence is, as shown in many reports, not markedly dissimilar. Of the patients who develop a recurrence after ileorectal anastomosis, only about half will have to have their anastomoses taken down. In our study, $59 \%$ of the patients had no recurrence and another $20.5 \%$ had a recurrence but did not require 'take down' of the anastomosis. Thus, almost $80 \%$ of our patients at the time of this report have been able to lead a life unencumbered by an ileostomy, making ileorectal anastomosis for this disease a desirable procedure to consider in selected patients.

There has been much discussion and controversy concerning the practicality of performing an ileorectal anastomosis after colectomy for Crohn's colitis. The surgeon may choose to leave the rectum in situ either because he considers the patient to be a poor surgical risk or because the rectum appears to be normal or near normal at the time of surgery. Total colectomy with ileostomy and mucous fistula is the most frequently performed operation for extensive Crohn's colitis, but it is our contention that either a primary ileorectal anastomosis or an ileorectal anastomosis after a total colectomy and ileostomy is a preferable procedure in selected cases.

The purpose of this study was to analyze our results in a group of 37 pationts with Crohn's disease of the colon who were treated by colectomy and ileorectal anastomosis so as to have a basis for comparison with the results obtained with colectomy

Address for reprint requests: Dr L. Wise, Chairman, Department of Surgery, Long Island Jewish-Hillside Medical Center, New Hyde Park, N.Y., 11040 U.S.A.

Received for publication 24 September 1976 and ileostomy for the same disease.

\section{Methods}

PATIENTS

During the period from 1955 to 1976, 103 patients had colon resections for Crohn's colitis at the Long Island Jewish-Hillside Medical Center (Table 1). The pathological diagnosis was made in conformity with criteria set forth by Lockhart-Mummery and Morson $(1960,1964)$.

Of the 37 patients considered in this study 29 had a colectomy and primary ileorectal anastomosis, five had secondary ileorectal anastomosis subsequent to subtotal colectomy and ileostomy, and three had ileorectal anastomosis secondary to segmental resection. None of the 37 patients had rectal involvement but $10(27 \%)$ of the patients had ileal involvement at the time of surgery. Sixteen patients had a protecting loop ileostomy constructed at the time of their ileorectal anastomosis. In this group there were 25 females and 12 males. Their ages ranged from 
Table 1 One hundred and three colon resections for Crohn's disease

\begin{tabular}{ll}
\hline Operation & Number of patients \\
\hline Proctocolectomy & 15 \\
Ileo-Rt. colon resection & 22 \\
Segmental resection & $16^{*}$ \\
Total colectomy and ileorectal anastomosis & 29 \\
Subtotal colectomy, ileostomy, and sigmoid & \\
$\quad$ fistula & $21 \dagger$ \\
Total & 103 \\
\hline
\end{tabular}

* Three patients subsequently converted to ileorectal anastomosis. †Five patients subsequently converted to ileorectal anastomosis.

10 to 72 years with an average of 31.3 years. Three patients died postoperatively and another five patients have had less than a one year follow-up. The other 29 patients have been followed from one to 21 years with a mean and median follow-up of 5,8 and six years respectively. No patient has been lost to follow-up.

\section{Results}

Of the 37 patients three developed anastomotic leaks, and all three patients died. Two of the patients who had leaks had a grossly normal ileum and rectum at the time of anastomosis. The third patient had ileal disease and a normal rectum. All patients who leaked had a primary ileorectal anastomosis without a protecting loop ileostomy. The sixteen patients who had a diverting loop ileostomy constructed at the time of anastomosis did not develop any anastomotic leakage either before or after the ileostomy was closed.

Of the 29 cases, followed up from one to 21 years, 12 patients had recurrences in the ileum or rectum and seven of these patients have had their anastomosis taken down. Table 2 illustrates an analysis of these 12 recurrences. The presence or absence of granulomas or of ileal involvement constituted no particular pattern in relation to recurrence. There were eight rectal recurrences. No patient in our total series of 103 patients presented with or developed carcinoma during the follow-up period.

When recurrences required surgery because of severe pain, bleeding, obstruction, perforation, fistula or diarrhea, abdominoperineal resection, and ileostomy was performed if the rectum was diseased. However, in two patients the recurrence was severe but confined to the ileum and in these patients a Hartman procedure and ileostomy was performed. Four of the anastomoses were taken down within three years of surgery, one after seven years and two after 10 years.

Five patients with recurrent disease still have their anastomoses intact and have gone for three to six years since the recurrence was noted. Allarefunctioning well with these recurrences and have no incapacitating diarrhoea or pain. The remaining 17 patients show no evidence of recurrence during a follow-up of up to 21 years.

\section{Discussion}

The surgical management of patients with Crohn's colitis is controversial. Proctocolectomy with ileostomy is the most frequently used surgical procedure but several reports have been published showing favourable results after ileorectal anastomosis in selected patients with a macroscopically normal or mildly diseased rectum. It was our purpose to evaluate the effectiveness and practicality of ileorectal anastomosis in such a group of patients. The major clinical problem in Crohn's colitis is the recurrence rate after operation. Studies reveal a wide

Table 2 Recurrences in cases of Crohn's disease with ileorectal anastomosis

\begin{tabular}{|c|c|c|c|c|c|c|c|}
\hline Sex & $\begin{array}{l}\text { Age }(y r) \\
\text { at anast. }\end{array}$ & $\begin{array}{l}\text { Duration of } \\
\text { disease before } \\
\text { anast. }(y r)\end{array}$ & Gran. & $\begin{array}{l}\text { Ileum before } \\
\text { anast. }\end{array}$ & $\begin{array}{l}\text { Ileal recurrence } \\
\text { and time } \\
\text { since anast. } \\
(y r)\end{array}$ & $\begin{array}{l}\text { Rectal recurrence } \\
\text { and time } \\
\text { since anast. } \\
(y r)\end{array}$ & $\begin{array}{l}\text { State of anastomosis } \\
(y r)\end{array}$ \\
\hline $\mathbf{F}$ & 23 & 3 & * & $\dagger$ & *3 mo. & $* 3 \mathrm{mo}$. & A-P resect. 2 \\
\hline $\mathbf{M}$ & 45 & 10 & - & $t$ & & - & Hartmann 1 \\
\hline $\mathbf{F}$ & 45 & 11 & $*$ & - & $* 1$ & $* 1$ & A-P resect. 3 \\
\hline $\mathbf{M}$ & 19 & 2 & - & - & - & $* 2$ & A-P resect. 2 \\
\hline $\mathbf{F}$ & 36 & 7 & $*$ & - & - & $* 3 \mathrm{mo}$ & A-P resect. 7 \\
\hline $\mathbf{M}$ & 13 & 2 & - & - & - & $* 10$ & A-P resect. 10 \\
\hline $\mathbf{F}$ & 25 & 9 & - & $\dagger$ & $* 5$ & - & Hartmann 10 \\
\hline $\mathbf{M}$ & 30 & 15 & - & - & - & $* 3$ & Good 3 \\
\hline $\mathbf{F}$ & 27 & 10 & - & - & - & $* 5$ & Fair 10 \\
\hline $\mathbf{F}$ & 40 & 10 & - & - & - & $* 6$ & Fair 8 \\
\hline $\mathbf{F}$ & 26 & 3 & $*$ & - & $* 5$ & - & Good 9 \\
\hline $\mathbf{F}$ & 21 & 11 & * & - & $* 5$ & - & Fair 9 \\
\hline $\begin{array}{l}8 \mathrm{~F} \\
4 \mathrm{M}\end{array}$ & Aver: 29 & Aver: 8 & $5^{*}$ & $3^{*}$ & $\begin{array}{l}6^{*} \\
\text { (Aver: 2.9) }\end{array}$ & $\begin{array}{l}8^{*} \\
\text { (Aver: } 3.4 \text { ) }\end{array}$ & 7 taken down \\
\hline
\end{tabular}

: granuloma present.

$\dagger$ : ileum diseased. 
Table 3 Recurrent ileocolitis after ileorectal anastomosis in patients with Crohn's disease

\begin{tabular}{lcl}
\hline Author & $\begin{array}{l}\text { Patients } \\
(\text { no. })\end{array}$ & $\begin{array}{l}\text { Recurrent ileocolitis } \\
(\%)\end{array}$ \\
\hline Nugent et al. $(1973)$ & 18 & 66 \\
Veidenheimer et al. (1970) & 7 & 42 \\
Burman et al. (1971) & 25 & 60 \\
Jones et al. $(1966)$ & 38 & 32 \\
Turnbull et al. (1968) & 22 & 32 \\
De Dombal et al. (1971) & 12 & 45 \\
Glotzer et al. $(1967)$ & 7 & 58 \\
Baker (1971) & 26 & 50 \\
Present study & 37 & 32 \\
Average & & 47 \\
\hline
\end{tabular}

variance but in general there is about a $50 \%$ recurrence rate of patients who underwent a colon resection and ileorectal anastomosis (Table 3).

There are multiple factors that have been analysed as to their effect on recurrence. Lindner et al. (1963), Janowitz et al. (1965) and Farmer et al. (1968) all stated that recurrence was related to concomitant ileal disease. In two small series of patients both Burman et al. (1971) and Veidenheimer et al. (1970) reported that the recurrence rate was highest if the edges used for anastomosis were macroscopically involved. Burman has stated that the recurrence rate was $78 \%$ in patients who had macroscopically diseased bowel at the level of the anastomosis and only a $50 \%$ recurrence if the bowel was macroscopically normal. The age of the patient at the time of ileorectal anastomosis has also been shown to influence the recurrence rate; the younger patients having the highest recurrence rate (Stahlgren and Ferguson, 1961; De Dombal et al., 1971; Steinberg et al., 1974). Glass and Baker (1976) have recently stated that the presence or absence of granuloma also has an effect on recurrence. Patients with granulomatous disease have half the number of recurrences as those with non-granulomatous Crohn's colitis. This finding suggests that sarcoid-like granulomata reflect the patient's immune response. Cornes et al. (1961), Jones et al. (1966), and De Dombal et al. (1971) have shown that the risk of recurrence is less in patients with involvement of only the large intestine.

The patient with extensive Crohn's colitis who needs surgical treatment can be treated by one of several surgical procedures. Total proctocolectomy, or colectomy with ileostomy and mucous fistula both necessitate the patient's wearing an appliance. There is only one procedure, ileorectal anastomosis, which allows the preservation of intestinal continuity for the patient with extensive Crohn's colitis. The results of this procedure must then be compared with the alternative procedures. It should be reiterated that ileorectal anastomosis can be performed safely only in selected patients. Patients with deep anal fistulas, incontinence, obstruction, severe stricture, a badly diseased rectum, perforation, toxic megacolon, severe ileal disease, or overwhelming sepsis are, by our criteria, poor candidates for this technique.

In our series of patients, three of the 37 patients $(8,1 \%)$ had anastomotic leaks and these three patients died. It is however, apparent that leakage can be eliminated as a complication by using a diverting loop ileostomy. Disease recurrence is apparently the most important factor to be considered before advising ileorectal anastomosis. In our series, pathological involvement of the anastomosed bowel or the presence or absence of granuloma did not affect recurrence, and, although pathological involvement of the anastomosed bowel leaves the patient liable to failure of the anastomosis, it does not mean that the anastomosis is doomed to failure.

When an analysis is made of several series of patients in whom an ileostomy was performed in conjunction with either a total proctocolectomy or total colectomy, the rate of recurrence in the ileostomy or just proximal to the stoma requiring stoma revision varied between $3 \%$ and $52 \%$ (Table 4 ). The average rate of ileal recurrence was $25 \%$. When this is compared with the various series using ileorectal anastomosis, we see a $47 \%$ incidence of recurrent ileocolitis (Table 3). The ranges of the lengths of follow-up are similar, but, in order to make a valid comparison between Tables 3 and 4, the mean and median of the length of follow-up must be known. Unfortunately, these parameters are not given in most of the studies. The reported incidence of ileostomy revision ranges from $10 \%$ to $33 \%$. This is not dissimilar from the rate of reoperation in patients with ileorectal anastomosis. Our incidence of recurrence was $32 \%$, with a reoperative rate of $21 \%$. Aside from occasional reports with recurrences of $3 \%$, the incidence of ileitis after ileostomy is not markedly dissimilar from the recurrence rate after ileorectal anastomosis. Thus, if we must choose

Table 4 Recurrent ileitis after colectomy and ileostomy for Crohn's disease

\begin{tabular}{llc}
\hline Author & $\begin{array}{l}\text { Patients } \\
(\text { no. })\end{array}$ & $\begin{array}{l}\text { Ileal recurrence } \\
(\%)\end{array}$ \\
\hline Nugent et al. (1973) & 44 & 3 \\
Steinberg et al. $(1974)$ & 73 & 33 \\
Hawk and Turnbull (1966) & 87 & 20 \\
Cooke (1971) & 31 & 52 \\
Glotzer et al. (1970) & 42 & 33 \\
Korelitz et al. $(1972)$ & 31 & 46 \\
De Dombal et al. (1971) & 39 & 11 \\
Jones et al. (1966) & 28 & 3 \\
Average & & 25 \\
\hline
\end{tabular}


between ileorectal anastomosis and a colectomy with an ileostomy, it is felt that ileorectal anastomosis should be undertaken in selected patients with Crohn's disease of the colon.

\section{References}

Baker, W. N. W. (1971). Ileorectal anastomosis for Crohn's disease of the colon. Gut, 12, 427-431.

Burman, J. H., Cooke, W. T., and Williams, J. A. (1971). The fate of ileorectal anastomosis in Crohn's disease. Gut, 12, 432-436.

Cooke, W. T., as cited by Burman, J. H., Cooke, W. T., and Williams, J. A. (1971) in: The fate of ileorectal anastomosis in Crohn's disease. Gut, 12, 432-436.

Cornes, J. S., and Stecker, M. (1961). Primary Crohn's disease of the colon and rectum. Gut, 2, 189-201.

De Dombal, F. T., Burton, I., and Goligher, J. C. (1971). Recurrence of Crohn's disease after primary excisional surgery. Gut, 12, 519-527.

Farmer, R. G., Hawk, W. A., and Turnbull, R. B. (1968), Regional enteritis of the colon: a clinical and pathological comparison with ulcerative colitis. American Journal of Digestive Diseases, 13, 501-514.

Glass, R. E., and Baker, W. N. W. (1976). Role of the granuloma in recurrent Crohn's disease. Gut, 17, 75-77.

Glotzer, D. J., Gardner, R. C., Goldman, H., Hinrichs, H. R. Rosen, H., and Zetzel, L. (1970). Comparative features and course of ulcerative and granulomatous colitis. New England Journal of Medicine, 282, 582-587.

Glotzer, D. J., Stone, P. A., and Patterson, J. F. (1967). Prognosis after surgical treatment of granulomatous colitis. New England Journal of Medicine, 277, 273-279.

Hawk, W. A., and Turnbull, R. B., Jr. (1966). Primary ulcerative disease of the colon. Gastroenterology, 51,
802-805.

Janowitz, H. D., Lindner, A. E., and Marshak, R. H. (1965). Granulomatous colitis: Crohn's disease of the colon. Journal of the American Medical Association, 191, 825-828.

Jones, J. H., Lennard-Jones, J. E., and Lockhart-Mummery, H. E. (1966). Experience in the treatment of Crohn's disease of the large intestine. Gut, 7, 448-452.

Korelitz, B. I., Present, D. H., Alpert, L. I., Marshak, R. H., and Janowitz, H. D. (1972). Recurrent regional ileitis after ileostomy and colectomy for granulomatous colitis. New England Journal of Medicine, 287, 110-115.

Lindner, A. E., Marshak, R. H., Wolf, B. S., and Janowitz, H. D. (1963). Granulomatous colitis: clinical study. New England Journal of Medicine, 269, 379-385.

Lockhart-Mummery, H. E., and Morson, B. C. (1960). Crohn's disease (regional enteritis) of the large intestine and its distinction from ulcerative colitis. Gut, 1, 87-105.

Lockhart-Mummery, H. E., and Morson, B. C. (1964). Crohn's disease of the large intestine. Gut, 5, 493-509.

Nugent, F. W., Veidenheimer, M. C., Meissner, W. A., and Haggitt, R. C. (1973). Prognosis after colonic resection for Crohn's disease of the colon. Gastroenterology, 65, 398-402.

Stahlgren, L. H., and Ferguson, L. K. (1961). The results of surgical treatment of chronic regional enteritis. Journal of the American Medical Association, 175, 986-989.

Steinberg, D. M., Allan, R. N., Thompson, H., Brooke, B. N., Alexander-Williams, J., and Cooke, W. T. (1974). Excisional surgery with ileostomy for Crohn's colitis with particular reference to factors affecting recurrence. Gut, $15,845-851$.

Turnbull, R. B., Schofeld, P. F., and Hawk, W. A. (1968). Non-Specific ulcerative colitis. Advances in Surgery, 3, 161-225.

Veidenheimer, M. C., Dailey, T. H., and Meissner, W. A. (1970). Ileorectal anastomosis for inflammatory disease of the large bowel. American Journal of Surgery. 119, 375-378. 